\title{
Effect of Nitrogen on the Growth of Boron Doped Single Crystal Diamond
}

\author{
Sunil Karna ${ }^{1} \&$ Yogesh Vohra ${ }^{1}$ \\ ${ }^{1}$ University of Alabama at Birmingham, AL, USA \\ Correspondence: Sunil Karna, University of Alabama at Birmingham, AL, USA. E-mail: skkarna@uab.edu
}

Received: October 8, 2013 Accepted: October 31, 2013 Online Published: November 18, 2013

doi:10.5539/jmsr.v3n1p43 URL: http://dx.doi.org/10.5539/jmsr.v3n1p43

\begin{abstract}
Boron-doped single crystal diamond films were grown homoepitaxially on synthetic (100) Type Ib diamond substrates using microwave plasma assisted chemical vapor deposition. A modification in surface morphology of the film with increasing boron concentration in the plasma has been observed using atomic force microscopy. Use of nitrogen during boron doping has been found to improve the surface morphology and the growth rate of films but it lowers the electrical conductivity of the film. The Raman spectra indicated a zone center optical phonon mode along with a few additional bands at the lower wavenumber regions. The change in the peak profile of the zone center optical phonon mode and its downshift were observed with the increasing boron content in the film. However, sharpening and upshift of Raman line was observed in the film that was grown in presence of nitrogen along with diborane in process gas.
\end{abstract}

Keywords: epitaxial, semiconductor, diamond, spectroscopy, thin-film

\section{Introduction}

Doped diamond films are of interest because of their potential use in the semiconductor industry as well as other applications involving their unique thermal, mechanical and chemical properties. Doping of diamond with boron during its growth process is a widely investigated field of research (Gheeraert et al., 1998; Issaoui et al., 2010; Ramamurti et al., 2009; Teraji et al., 2004). Boron provides diamond a wide range of dopant concentrations (10 ${ }^{16}$ up to $10^{21}$ atom $\mathrm{cm}^{-3}$ ) from a wide band gap semiconductor to a metal and to a superconductor (Bustarret et al., 2008; Kraft, 2007; Mavrin et al., 2008). However, the large scale production of doped diamond film can be possible only if high growth rate and high crystalline quality can be achieved simultaneously. It has been reported that the use of nitrogen during deposition improves the growth rate of diamond films (Hemley et al., 2005; Horino et al., 2006; Theije et al., 2000). The catalytic effect of parts per million nitrogen impurity on homoepitaxial diamond growth has been extensively investigated and exploited in the high growth rate experiments. Similarly, boron doped homoepitaxial diamond growth has been investigated for the semiconducting diamond studies. In this paper, we have investigated simultaneous effects of nitrogen and boron in the homoepitaxial diamond growth and shown that an optimal growth conditions with low surface roughness and high growth rate can be achieved in doped diamond. In particular, we have investigated the effect of nitrogen on growth morphology and growth rate of diamond films during boron doping and also studied their electrical conductivity as a function of temperature.

\section{Method}

Synthetic (100) oriented Type Ib diamond substrates (size $3.5 \times 3.5 \times 1.5 \mathrm{~mm}^{3}$ ) were chosen as seed crystals for this study. The diamond seed crystals cleaned in acetone were inserted into $2.45 \mathrm{GHz}$ microwave reactor chemical vapor deposition (CVD) chamber. The microwave power was adjusted to $1.4-1.5 \mathrm{~kW}$ to set a deposition temperature of $1100 \pm 20{ }^{\circ} \mathrm{C}$ at a chamber pressure of 100 Torr. The $10 \% \mathrm{~B}_{2} \mathrm{H}_{6}$ diluted in $\mathrm{H}_{2}$ with $6 \%$ of $\mathrm{CH}_{4} / \mathrm{H}_{2}$ mixture was used for the deposition with a total of 400 standard cubic centimeters per minute (sccm) of gas. The details of deposition parameters and growth rate of samples have been summarized in Table 1. Each sample was ultrasonicated in acetone after deposition to remove any residual boron-carbon soot. The quality and surface morphology of as deposited films were determined by Raman spectroscopy, X-ray rocking curve experiment, optical microscopy (OM) and atomic force microscopy (AFM). Raman spectra were recorded using a $514 \mathrm{~nm}$ laser excitation wavelength at room temperature. In the X-ray rocking curve experiment, omega scans were obtained by rotating sample with $0.02^{\circ}$ angular step with a detector fixed at $2 \theta$ position corresponding to 
(400) Bragg diffraction peak. Type of doping, doping level and electrical conductivity was determined by room temperature Hall measurement and four point probe measurements respectively. In a four point probe measurement, the samples were first heated to $600 \mathrm{~K}$ and the electrical resistance was measured during the cool down process. This procedure was followed to remove any adsorbates from the diamond films that could have arisen from the CVD shut down procedure in hydrogen atmosphere. The I-V characteristics were maintained in the linear regime during experiment by limiting the current supply to $1 \mathrm{~mA}$ at zero-magnetic field. The value of sheet resistance was measured in magnetic field of 0.55 Tesla. The measurements were taken for both positive and negative current with both polarities of magnetic field.

Table 1. Growth conditions, Growth rate [r] and bulk carrier concentrations [ $\eta]$ of grown diamond films.

\begin{tabular}{cccccc}
\hline Sample & $\begin{array}{c}\mathrm{B}_{2} \mathrm{H}_{6} \\
(\mathrm{ppm})\end{array}$ & $\begin{array}{c}{[\mathrm{B} / \mathrm{C}]_{\mathrm{gas}}} \\
(\mathrm{ppm})\end{array}$ & $\begin{array}{c}\mathrm{N}_{2} \\
(\mathrm{ppm})\end{array}$ & $\begin{array}{c}{[\mathrm{r}]} \\
(\mu \mathrm{m} / \mathrm{hr})\end{array}$ & $\begin{array}{c}{[\eta]} \\
\left(\mathrm{cm}^{-3}\right)\end{array}$ \\
\hline $\mathrm{HD} 2$ & 0 & 0 & 0 & 10 & $5.5 \times 10^{17}$ \\
$(\mathrm{BD} 5)$ & 150 & 5000 & 0 & 6 & $1.0 \times 10^{19}$ \\
$(\mathrm{BD} 6)$ & 250 & 8000 & 0 & 5 & $6.6 \times 10^{19}$ \\
$(\mathrm{BD} 7)$ & 500 & 16,000 & 0 & 4 & $2.3 \times 10^{20}$ \\
$(\mathrm{BD} 8)$ & 500 & 16,000 & 1000 & 6 & $3.9 \times 10^{19}$ \\
$(\mathrm{BD} 9)$ & 500 & 16,000 & 2000 & 12 & - \\
\hline
\end{tabular}

\section{Results and Discussion}

In order to study the effect of nitrogen on growth morphology of boron doped diamond, a few samples were grown at varying diborane and nitrogen contents in the feed gas. The deposition time for diamond film growth has been set for 5 hours. After doping the color of seed had been found to change from yellowish to pale blue, then to dark blue and finally opaque to visible light depending upon the increasing boron concentration in the films. Optical transmission spectra of the samples in the visible range were taken in order to measure the effect of doping on the color of the films as shown in Figure 1. The spectra indicate small downshift of peak and decrease in intensity as the doping level of the films increases. The peak of low doped film (sample BD5) appeared at $454 \mathrm{~nm}$ in the optical transmission spectra (Figure 1). The surface morphology of films was analysed using OM and AFM. The AFM images taken over scanned areas of $10 \times 10 \mu \mathrm{m}^{2}$ are shown in Figure $2(\mathrm{a}, \mathrm{b}$ and c). The untreated substrate samples (seeds) are macroscopically flat. The OM image of undoped diamond film (HD2) shows some hillocks on its surface as shown in Figure 2(a). The growth rate and surface morphology are observed to be dependent on $\mathrm{B} / \mathrm{C}$ ratio in the gas phase. Increasing $\mathrm{B} / \mathrm{C}$ ratio up to a certain limit in feed gas decreases the growth rate as well as the surface roughness. The surface smoothness of the film was observed to be improving with an additional supply of $1000 \mathrm{ppm}$ of nitrogen in feed gas as shown by a comparison of sample BD7 (16,000 ppm of $\mathrm{B}_{2} \mathrm{H}_{6}$ and no $\mathrm{N}_{2}$ ) and BD8 (addition of $1000 \mathrm{ppm}$ of N2) in Figure 2(b) and Figure 2(c). However, hillocks were observed on the surface of film with the addition of $2000 \mathrm{ppm}$ of nitrogen in BD9 as shown in Figure 2(c). On contrary the growth rate of diamond films were improved by a factor two in comparision to that using $1000 \mathrm{ppm}$ of nitrogen as shown in Table 1 of samples BD8 and BD9. The root mean square (rms) roughness of the samples measured from contact mode AFM images of the surface are listed in parenthesis for each sample Seed $(1.6 \mathrm{~nm}), \mathrm{HD} 2(2 \mathrm{~nm})$, BD5 $(4 \mathrm{~nm})$, BD6 $(1.6 \mathrm{~nm})$, BD7 $(1 \mathrm{~nm})$, BD8 $(0.8 \mathrm{~nm})$ and BD9 $(0.9 \mathrm{~nm})$ and was found to decrease with increasing boron concentration. Introduction of $1000 \mathrm{ppm}$ of nitrogen during boron doping improved the surface morphology and increased the growth rate of film (sample BD8). However, when higher amount of nitrogen $(2000 \mathrm{ppm})$ along with the same $\mathrm{B} / \mathrm{C}$ ratio $(16,000 \mathrm{ppm})$ was used, the film growth rate was shown to increase by twice than that using $1000 \mathrm{ppm}$ of nitrogen with the cost of surface quality degradation. When very high $\mathrm{B} / \mathrm{C}$ ratio $(25,000 \mathrm{ppm})$ or very high methane $10 \%$ of total feed gas was introduced in the deposition chamber, amorphous carbon and polycrystalline diamond film grew on the seed crystal. Hence, it can be argued that an optimal amount of diborane and nitrogen is needed to improve the structural quality and the growth rate of boron doped single crystal diamond. The quality of the epitaxial diamond film determined using X-ray rocking curve and Raman spectroscopy is shown in Figure 3. A single intense peak of (400) was observed in the rocking curve experiment from 30 through $62^{\circ}$ omega scans indicates 
high quality film as shown in the inset of Figure 3. The measured full width at half maximum (FWHM) of the Bragg peak varies from $0.07^{\circ}$ to $0.11^{\circ}$ as the boron content in the films is increased indicating the decrease in structural quality.

An intense zone-center optical phonon mode of diamond is visible at $1333 \mathrm{~cm}^{-1}$ along with additional bands at $586,910,1040,1233 \mathrm{~cm}^{-1}$ as shown in Figure 3. Significant modification and asymmetry in zone center optical phonon line was observed in the presence of such additional bands. In low boron doped films, these bands were absent and no asymmetry in Raman line was observed. Those additional bands were previously reported on both the boron doped polycrystalline and single crystal diamond (Bustarret et al., 2008; Karna et al., 2013; Pruvost \& Deneuville, 2000; Wang et al., 2002). The asymmetry in optical phonon Raman line has been found to increase with increasing doping level. The downshift of optical phonon line and broadening of FWHM with doping level were also observed in the spectrum. The Raman line of boron doped samples has been observed to be sharpened and shifted towards higher wavenumber region when the sample was grown in presence of nitrogen. The downshift of optical phonon line with increasing boron content has already been described (Gheeraert et al., 1993). The bands around 1233 and $580 \mathrm{~cm}^{-1}$ are assigned due to large cluster of boron atoms present in diamond lattice (Mavrin et al., 2008, Wang et al., 2002, Kawano et al., 2010). The asymmetric broadening and downshift of Raman peak of boron-doped diamond films could be explained by Fano-effect (Mitani et al., 2012; Nebel \& Ristein, 2003; Pruvost \& Deneuville, 2001; Szirmai et al., 2012; Werner et al., 1996). The variation in conductivity, $(\sigma)$ of the films with temperature $(\mathrm{T})$ was determined from four point probe measurement as shown in Figure 4. Activation energies of the samples have been obtained by the best fit of the Arrhenius plot of the conductivity data in two different temperature regimes. The activation energies of samples BD6, BD7 and BD8 are $0.18,0.10$ and $0.16 \mathrm{eV}$ above transition point and $0.02,0.02,0.01 \mathrm{eV}$ below transition point respectively. The difference in activation energy from high to low temperature indicates that two different conduction mechanisms are responsible for carrier transport in the film (Walker \& Thrower, 1997; Werner et al., 1994). At higher temperatures, carriers are transported via band conduction and at low temperatures, carrier hops in the localized states via hopping conduction. At high temperature the activation energy of carriers was found to decrease with increasing doping concentration. Increasing doping concentration increases the acceptor band width which ultimately reduces the activation energy of acceptors (Szirmai et al., 2012). P-type doping was verified by Hall measurement. The boron concentrations in samples BD6, BD7 and BD8 calculated from room temperature Hall measurement were $6.6 \times 10^{19}, 2.3 \times 10^{20}$ and $3.9 \times 10^{19} \mathrm{~cm}^{-3}$ respectively and that from activation energy above transition point using Pearson and Barden formula were $2.0 \times 10^{19}, 0.6 \times 10^{20}$ and $2.7 \times 10^{19} \mathrm{~cm}^{-3}$ respectively (Pearson \& Bardeen, 1949).

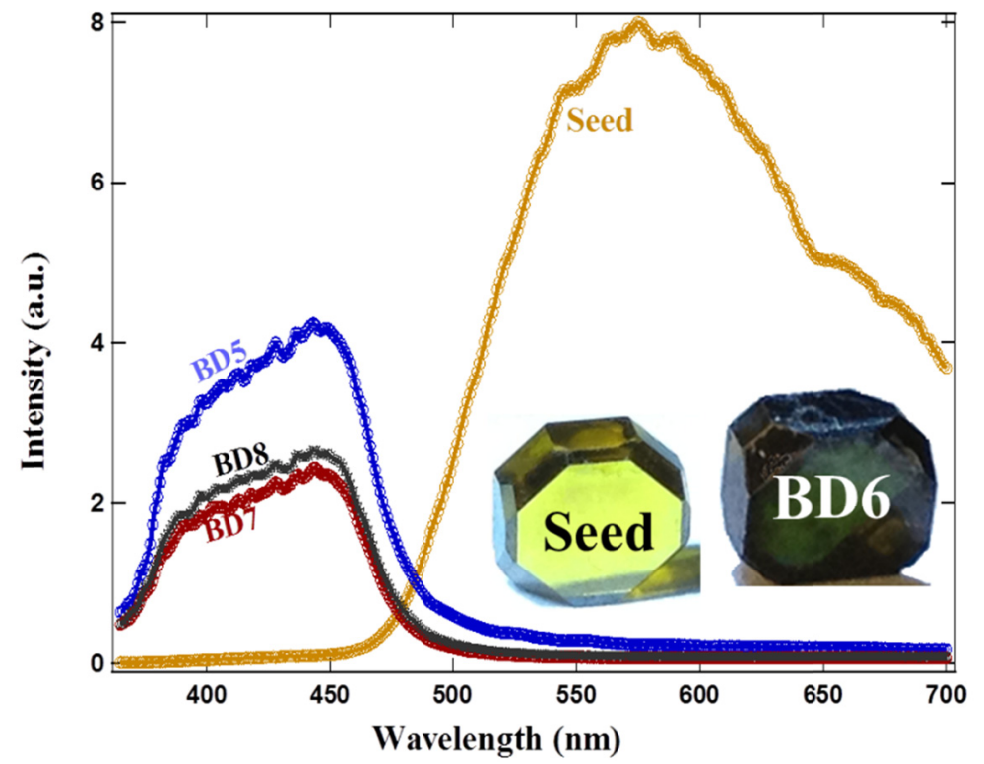

Figure 1. Optical transmission spectra of seed crystal (Seed) and doped diamond films after applying correction for the absorption in the diamond seed crystal. Photographs of seed crystal (Seed) and doped diamond (BD6) are embedded inside the graph. Yellow color is evidence of substitutional nitrogen atom in seed crystal and bluish color in BD6 represents presence of boron in diamond lattice 

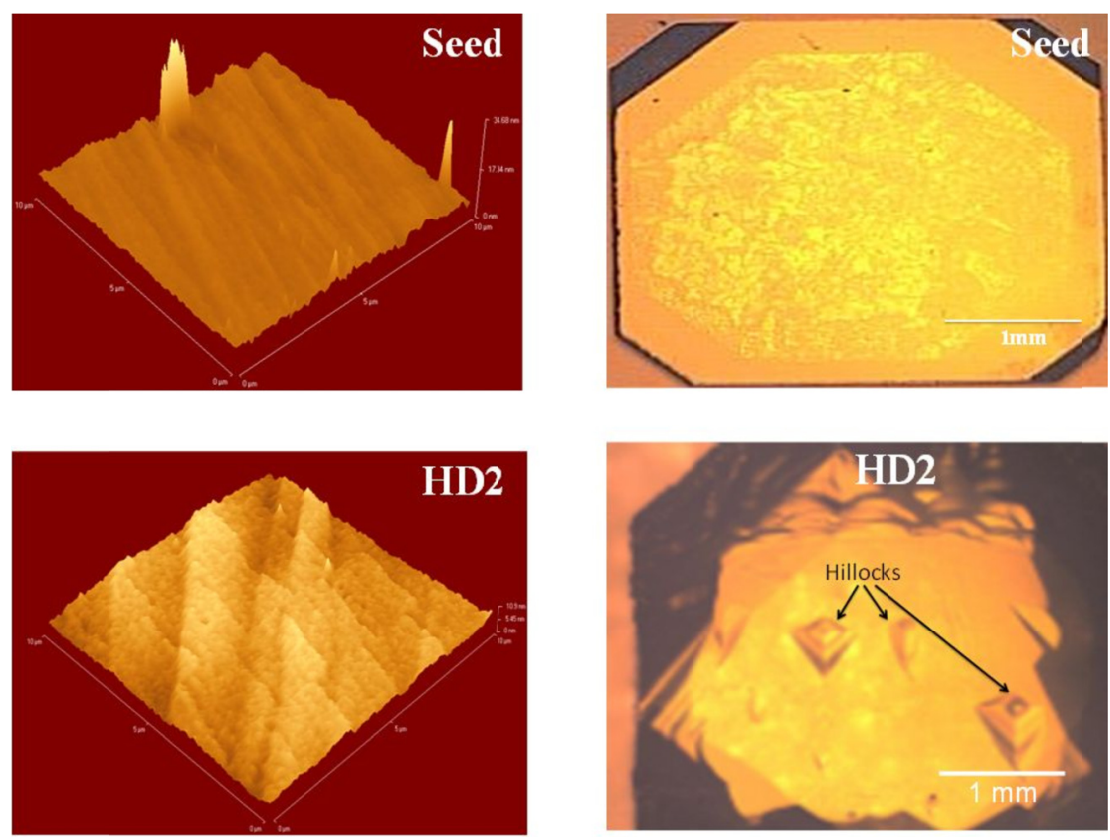

Figure 2(a). Atomic Force Microscopy (AFM-left) and Optical Microscopy (OM-right) images of untreated substrate (Seed) and as deposited undoped diamond film (HD2)
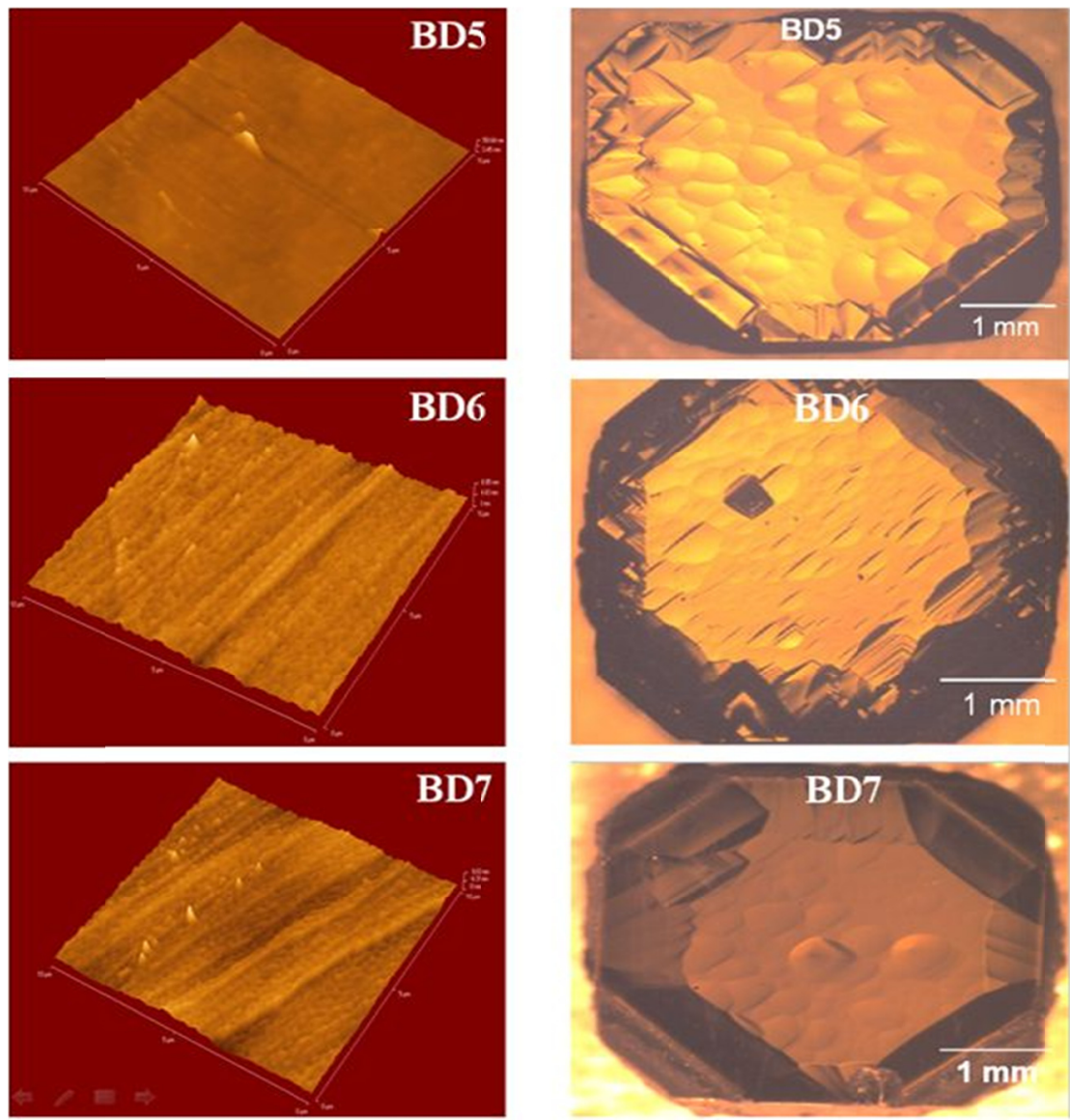

Figure 2(b). Atomic Force Microscopy (AFM-left) and Optical Microscopy (OM-right) images of as deposited boron-doped diamond films (BD5, BD6 and BD7) 

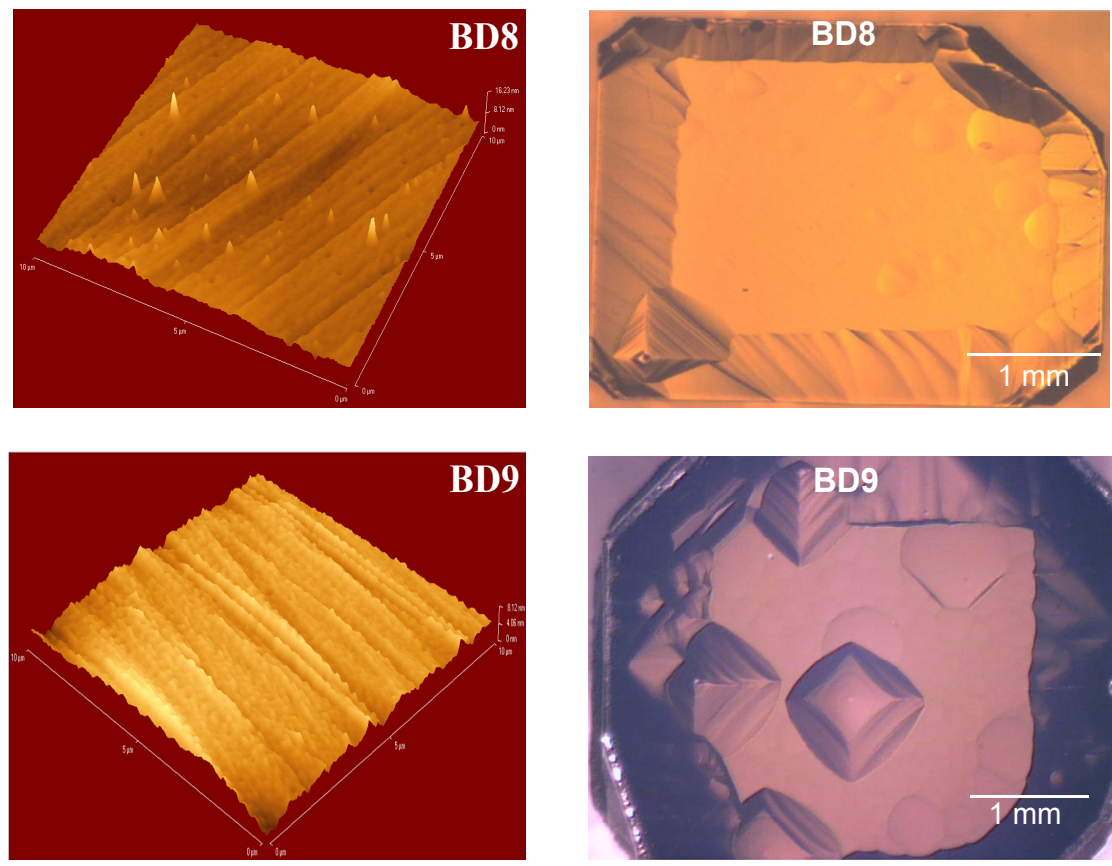

Figure 2(c). Atomic Force Microscopy (AFM-left) and Optical Microscopy (OM-right) images of as deposited boron-doped diamond films BD8 and BD9

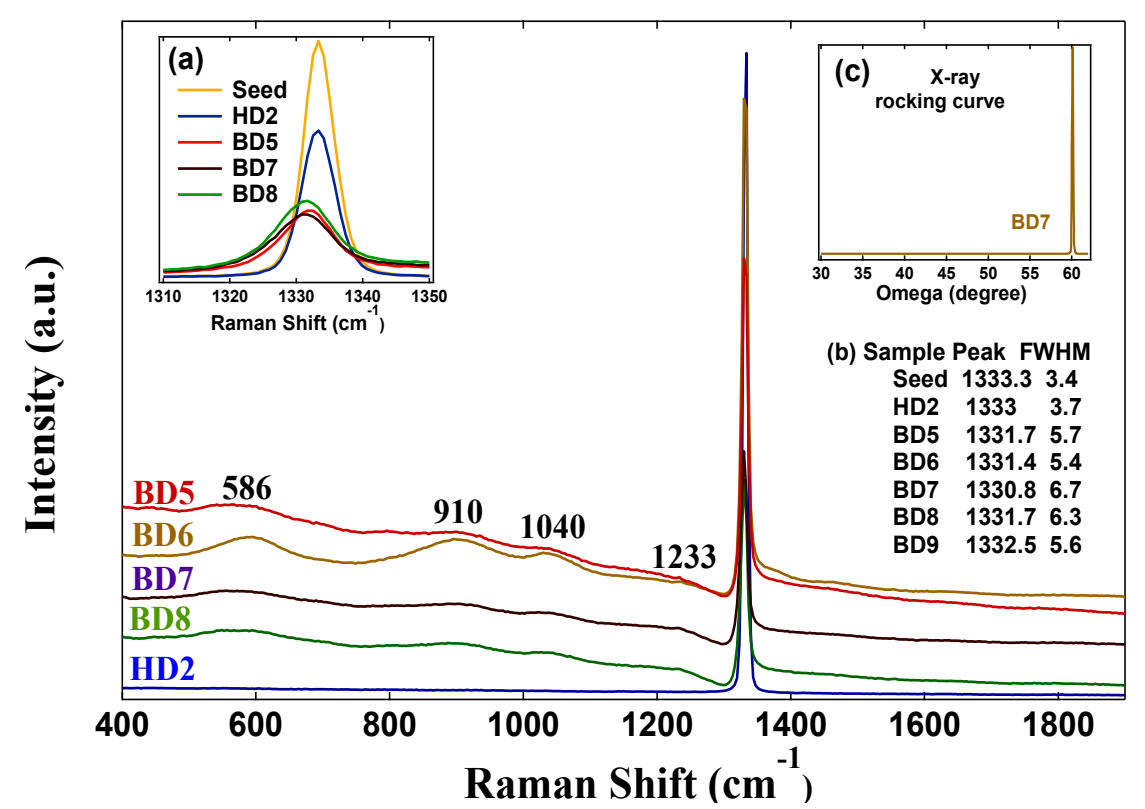

Figure 3. Raman spectra of Seed, undoped (HD2) and doped (BD5, BD6, BD7 and BD8) diamond films. The spectra are offset for clarity. The insert (a) and (b) provide peak location of Raman spectrum and Full Width at Half Maximum (FWHM) for the zone center Raman mode. The insert (c) shows the X-ray rocking curve for sample BD7 


\section{$\mathbf{T}(\mathbf{K})$}

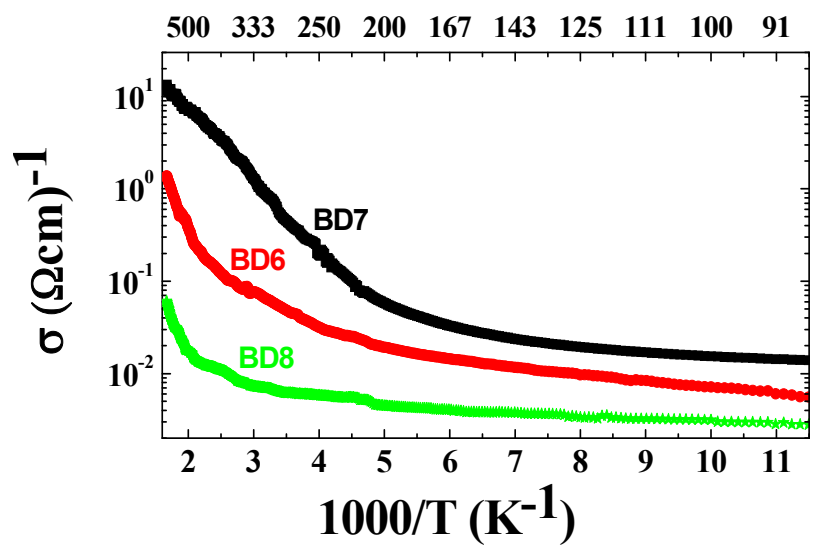

Figure 4. Four point probe measurement of electrical conductivity of boron doped diamond films BD6, BD7 and BD8 as a function of temperature. The observed transition temperature decreases with the increasing boron content of the film

\section{Conclusions}

Boron-doped single crystal diamonds have been synthesized using MPCVD method and effect of nitrogen during the growth process of boron-doped diamond has also been studied. The deposition shows that the color of seed crystal is being changed from yellow to pale blue then to dark blue as the boron concentration in the film is increased. Supply of $1000 \mathrm{ppm}$ of nitrogen in feed gas improves the surface morphology and increases the growth rate of diamond deposition. However, when $2000 \mathrm{ppm}$ of nitrogen was introduced in feed gas, growth rate was double than that using $1000 \mathrm{ppm}$ of nitrogen with some non-epitaxial growth on the surface of doped film. Hence, it can be argued that an optimal amount of diborane and nitrogen is needed to improve the structural quality and the growth rate of boron doped single crystal diamond. A few additional bands along with first order Raman line were visible in the lower wavenumber region in Raman spectrum of boron-doped diamond films. The downshift and broadening of Raman line was also observed with increasing boron content in the crystal. The decrease in width and upward shift of Raman line was also observed in the samples that grew in presence of nitrogen. The growth rate of diamond was observed to be decreasing with increasing boron content in the film. Temperature dependent resistivity measurements showed that the current conduction mechanism depends upon the doping level and obeys semiconductor behaviour in the experimental temperature range of $140 \mathrm{~K}$ to $600 \mathrm{~K}$.

\section{Acknowledgements}

This material is based upon work supported by the Department of Energy National Nuclear Security Administration under Award Number DE-NA0002014. We are very thankful to Drs. Martyshkin, Dashdorje, and Kung for their help rendered during the characterization of deposited films. Sunil Karna gratefully acknowledges the graduate assistant fellowship from UAB.

\section{References}

Bustarret, E., Achatz, P., Sacepe, B., Chapelier, C., Marcenat, C., Ortega, L., \& Klein, T. (2008). Metal-to-insulator transition and superconductivity in boron-doped diamond. Phil. Trans. R. Soc. A., 366, 267. http://dx.doi.org/10.1098/rsta.2007.2151 PMid:18024360

Gheeraert, E., Deneuville, A., \& Mambou, J. (1998). Boron-related infra-red absorption in homoepitaxial diamond films. Diam. Rel. Mater., 7, 1509. http://dx.doi.org/10.1016/S0925-9635(98)00223-4

Gheeraert, E., Gonon, P., Deneuville, A., Abello, L., \& Lucazeau, G. (1993). Effect of boron incorporation on the quality of MPCVD diamond films. Diam. Rel. Mater., 2, 742. http://dx.doi.org/10.1016/0925-9635(93)90215-N

Hemley, R. J., Chen, Y. C., \& Yan, C. S. (2005). Growing Diamond Crystals by Chemical Vapor Deposition, Elements, 1, 105. http://dx.doi.org/10.2113/gselements.1.2.105

Horino, Y., Chayahara, A., Mokuno, Y., Yamada, H., \& Fujimori, N. (2006). Microwave plasma chemical vapor deposition with newly designed substrate holders. New Diam. \& Front. Carbon Technol., 16, 63. 
Issaoui, R., Achard, J., Silva, F., Tallaire, A., Tardieu, A., Gicquel, A., ... Jomard, F. (2010). Growth of thick heavily boron-doped diamond single crystals: Effect of microwave power density. Appl. Phys. Lett., 97, 182101. http://dx.doi.org/10.1063/1.3511449

Karna, S., Martyshkin, D., Vohra, Y., \& Weir, S. (2013). Synthesis and characterization of boron-doped single crystal diamond. MRS Proceedings, 1519.

Kawano, A., Ishiwata, H.. Iriyama, S., Okada, R., Yamaguchi, T., \& Takano, Y. (2010). Superconductor-to-insulator transition in boron-doped diamond films grown using chemical vapor deposition. Phys. Rev. B., 82, 085318. http://dx.doi.org/10.1103/PhysRevB.82.085318

Kraft, A. (2007). Doped Diamond: A Compact Review on a New Versatile Electrode Material, Int. J. Electrochem. Sci., 2, 355.

Mavrin, B. N., Denisov, V. N., Popova, D. M., Skryleva, E. A., Kuznetsov, M. S., Nosukhin, S. A., ... Blank, V. D. (2008). Boron distribution in the subsurface region of heavily doped IIb type diamond. Phys. Lett. A., 372(21) 3914. http://dx.doi.org/10.1016/j.physleta.2008.02.064

Mitani, T., Nakashima, S., Kojima, K., Kato, T., \& Okumura, H. (2012). Determination of carrier concentration by Fano interference of Raman scattering in heavily doped n-type 4H-SiC. J. Appl. Phys., 112, 043514. http://dx.doi.org/10.1063/1.4748279

Nebel, C., \& Ristein, J. (2013). Thin-Film Diamond I (p. 209). (I ed.), Elsevier.

Pearson, G., \& Bardeen J. (1949). Electrical Properties of Pure Silicon and Silicon Alloys Containing Boron and Phosphorus. Phys. Rev., 75, 865. http://dx.doi.org/10.1103/PhysRev.75.865

Pruvost, F., \& Deneuville, A. (2000). Characteristics of homoepitaxial heavily boron-doped diamond films from their Raman spectra. Diam. Rel. Mater., 9, 295. http://dx.doi.org/10.1016/S0925-9635(99)00241-1

Pruvost, F., \& Deneuville, A., (2001). Analysis of the Fano in diamond. Diam. Rel. Mater., 10, 531. http://dx.doi.org/10.1016/S0925-9635(00)00378-2

Ramamurti, R., Becker, M., Schuelke, T., Grotjohn, T. A., Reinhard, D. K. \& Asmussen, J. (2009). Deposition of thick boron-doped homoepitaxial single crystal diamond by microwave plasma chemical vapor deposition. Diam. Rel. Mater., 18, 704. http://dx.doi.org/10.1016/j.diamond.2009.01.031

Szirmai, P., Fabian, G., Koltai, J., Nafradi, B., Forro, L., Pichler, T., ... Simon, F. (2012). Raman measurements in superconducting boron doped diamond, arXiv:1204.5305v1.

Teraji, T., Arima, K., Wada, H., \& Ito, T. (2004). High quality boron-doped homoepitaxial diamond grown by high-power microwave-plasma chemical vapor deposition. J. App. Phys., 96, 5906. http://dx.doi.org/10.1063/1.1805180

Theije, F., Schermer, J., \& Enckevort, W. (2000). Effects of nitrogen impurities on the CVD growth of diamond: step bunching in theory and experiment. Diam. Rel. Mater., 9, 1439. http://dx.doi.org/10.1016/S0925-9635(00)00261-2

Walker P., \& Thrower P. (1997). Chemistry and physics of carbon (p. 34). New York: Marcel Dekker.

Wang, Y., Lau, S., Tay, B., \& Zhang, X. (2002). Resonant Raman scattering studies of Fano-type interference in boron doped diamond. J. Appl. Phys., 92, 7253. http://dx.doi.org/10.1063/1.1524018

Werner, M., Dorsch, B., Obermeier, E., Haase, L., \& Seifert, W. (1994). Charge transport in heavily B-doped polycrystalline diamond films. Appl. Phys. Lett., 64(5), 595. http://dx.doi.org/10.1063/1.111088

Werner, M., Job, R., Zaitzev, A., Faiirner, W., Seifert, W., \& Johnston, C. (1996). The relationship between resistivity and boron doping concentration of single crystal and polycrystalline diamond. Phys. Stat. Sol. (a), 154(1), 385-393. http://dx.doi.org/10.1002/pssa.2211540127

\section{Copyrights}

Copyright for this article is retained by the author(s), with first publication rights granted to the journal.

This is an open-access article distributed under the terms and conditions of the Creative Commons Attribution license (http://creativecommons.org/licenses/by/3.0/). 